\title{
MÉTODO GRĀFICO E ESTIMATIVA DE ÍNDICE ALIMENTAR APLICADO NO ESTUDO DE ALIMENTAÇÃO DE PEIXES
}

\author{
E.KAWAKAMI \\ Companhia de Tecnologia de Saneamento Ambiental - CETESB, S. Paulo, SP, Brasil
}

e

G. VAZZOLER

Instituto Oceanográfico da Universidade de São Paulo, São Paulo, SP, Brasil

\section{SYNOPSIS}

Using a figure which is a combination of volume percentage (Vi) in the axis of $x$ and frequency of occurrence percentage (Fi) in the axis of $\mathbf{y}$ it is possible to obtain paralelograms representing the relative importance of the food items. The paralelogram areas are proportional to the volume (\%) and frequency of occurrence (\%) products; such values are used to calculate a "feeding index" (IAi).

This "feeding index" is proposed as a new method to evaluate the true importance of each food item in the feeding spectrum of each species, as well as to contribute to the understanding of the relationships between several species when applied to fish fauna from the same place and at the same time.

Nos estudos sobre alimentação de peixes procura-se oferecer uma representação gráfica, geralmente sob a forma de diagrama de barra para a freqüência de ocorrência, e setorial para o volume, ou peso, dos componentes de cada ítem, que representa a posiçāo do mesmo dentro do espectro alimentar da espécie. É também mujto comum, na análise do regime alimentar, com a ajuda desses gráficos, usar-se expressões tais como "mais comum", "predominante", "mais importante", "domina", para consignar a posição dos ítens no espectro alimentar.

Basicamente dois são os aspectos mais importantes a considerar na avaliação do regime alimentar de peixes: 1) a freqüência com que um determinado ítem é consumido, e 2) o seu volume. Esses aspectos, e outros, são tratados segundo métodos consagrados na literatura, revistos e discutidos por Hynes (1950), e podem ser postos como segue:

a) frequêencia de ocorrência - corresponde à freqüência porcentual do número de estômagos onde ocorre determinado ítem alimentar em relação ao número de estômagos com alimento;

b) volumétrico - pelo qual o volume é expresso na forma porcentual, considerando o volume de dado ítem alimentar em relação ao volume de todos os ítens alimentares presentes nos estômagos.

Obtendo-se resultados por um dos métodos sua análise independente pode nos levar a estimativas errôneas, uma vez que nem sempre o item mais treqüente é o mais volumoso, e vice-versa o que pode falsear o significado do "mais freqüente", "mais comum" e etc., conduzindo a uma super ou subestimativa do "valor" do ítem no espectro alimentar.

Lande $(1973 ; 1976)$ conjugou em gráfico os valores porcentuais da frequêencia de ocorrência com os valores porcentuais do número de indivíduos de cada ítem, facilitando a compreensão do que é "mais importante". Cada ítem passa a ser representado por um quadrílátero, num sistema de coordenadas (freqüência de ocorrência \% ) na ordenada e porcentagem do número total de indivíduos por ítem, na abcissa), cujas dimensões oferecem a posição de cada item no espectro alimentar.

A nosso ver, a conjugação dos dois métodos referidos - frequêencia de ocorrência e volumétrico - é o ideal, permitindo uma avaliação mais real, sendo então os resultados expressos em termros de "os ítens principais na alimentação de (espécie) são...". Considerando-se que as áreas dos quadriláteros são proporcionais aos produtos dos valores porcentuais da freqüência de ocorrência e volume de cada ítem, poderemos utilizá-los para estimar a importância alimentar de cada ítem na alimentação de uma dada espécie. Desse modo, a partir da razão entre o produto da freqüência de ocorrência e volume, em ambos os casos em valores porcentuais, de cada ítem e da somatória dos produtos para todos os ítens constatados, será possivel estimar um "índice alimentar" para cada ítem, estabelecendo-se a seguinte relação:

$I A_{i}=\frac{F_{i} \times V_{i}}{\sum_{i=1}^{n}\left(F_{i} \times V_{i}\right)}$ onde:

$\mathrm{IA}_{\mathrm{i}}=$ ínciice alimentar

$\mathrm{i}=1,2, \ldots \mathrm{n}=$ determinado ítem alimentar

$\mathrm{F}_{\mathrm{i}}=$ freqüência de ocorrência $(\%)$ do determinado ítem

$\mathrm{V}_{\mathrm{i}}=$ volume $(\%)$ do determinado ítem

Tal "índice alimentar" permite-nos distinguir mais adequadamente a importância relativa de cada ítem, qualquer que seja sua condição quanto à freqüência de ocorrência e volume, valores esses que apenas lançados em gráfico combinado, poderiam aparecer sob a forma de quadriláteros diferentes que, visualmente, não possibilitariam avaliar de forma precisa a proporcionalidade de suas áreas.

As Figuras 1 e 2 representam os resultados obtidos por Kawakami (1975), para Etropus longimanus, utilizando cada método isoladamente. A Tabela I contém os dados relativos à frequiência dé ocorrência e volume porcentual, bem como os produtos desses valores e os "indices alimentares" de cada ítem.

A análise das Figuras 1 e 2 , respectivamente, permite-nos concluir que, em termos de frequêencia de ocorrência, o ítem predominante no inverno são os gamarídeos, e na nrimavera os gamarídeos e poliquetos; e, em termos volumetricos, o ftem predom1nante é constituido pelos poliquetos, tanto no inverno como na primavera.

A Figura 3 representa os resultados obtidos pela aplicação do novo método proposto; observa-se que no inverno os ítenș mais importantes na alimentação da espécie foram gamarídeos e poliquetos $(0,49$ e 0,45 , respectivamente, para valores de "índice alimentar") e na primavera, os poliquetos $(0,74$ para o "Indice alimentar"). No inverno, apesar do alto volume porcentual, os poliquetos possuem "índices alimentar" equivalente, ou mesmo um pouco mais baixo que os gamarídeos; na primavera, embora quase mantendo o mesmo valor de volume porcentual que no inverno, os poliquetos apresentam um "índice alimentar" bem mais elevado que os gamarídeos, devido à sua frequência ter sido, nessa época, bem mais elevada que no inverno.

Os demais itens representados por valores muito baixos, demonstram o seu valor secundário, ou mesmo acidental, na alimentação de $E$. longimanus.

Os "indices alimentares" determmam, craranente, a importância efetiva de cada item na alimentação da espécie. Permitem, ainda, uma avaliação quantitativa das variações espacial e temporal das disponibilidades quali e quantitativa dos diferentes itens alimentares para cada espécie estudada. A obtenção de informaçōes deste tipo, relativas a várias espécies que ocupam uma mesma região, poderá vir a constituir-se em importante subsídio para a compreensão da interação dos processos alimentares entre diferentes espécies de peixes.

Bibliografia

HYNES, H.B.N. 1950. The food of freshwater sticklebacks (Gasterosteus aculeatus and Pygosteus pungitus), with a review of methods used in studies of the food of fishes. J. Anim. Ecol., 19(1): 36-58.

KAWAKAMI, E. 1975. Álimentaçāo de Pleuronectiformes (Análise comparativa e bionomia). Dissertação de Mestrado. Universidade de São Paulo, Instituto Uceanogranico. 
LANDE, R. 1973. Food and feeding habits of plaice (Pleuronectes._platessa L.) in Borgenfjorden, North-Trondelag, Norway. Norw. J. Zool., $21: 91-100$.
- - 1976. Food and feeding habits of the dab (Limanda limanda (L.)) in Borgenfjorden, North-Trondelag, Norway. Norw. J. Zool., $24: 225-230$.

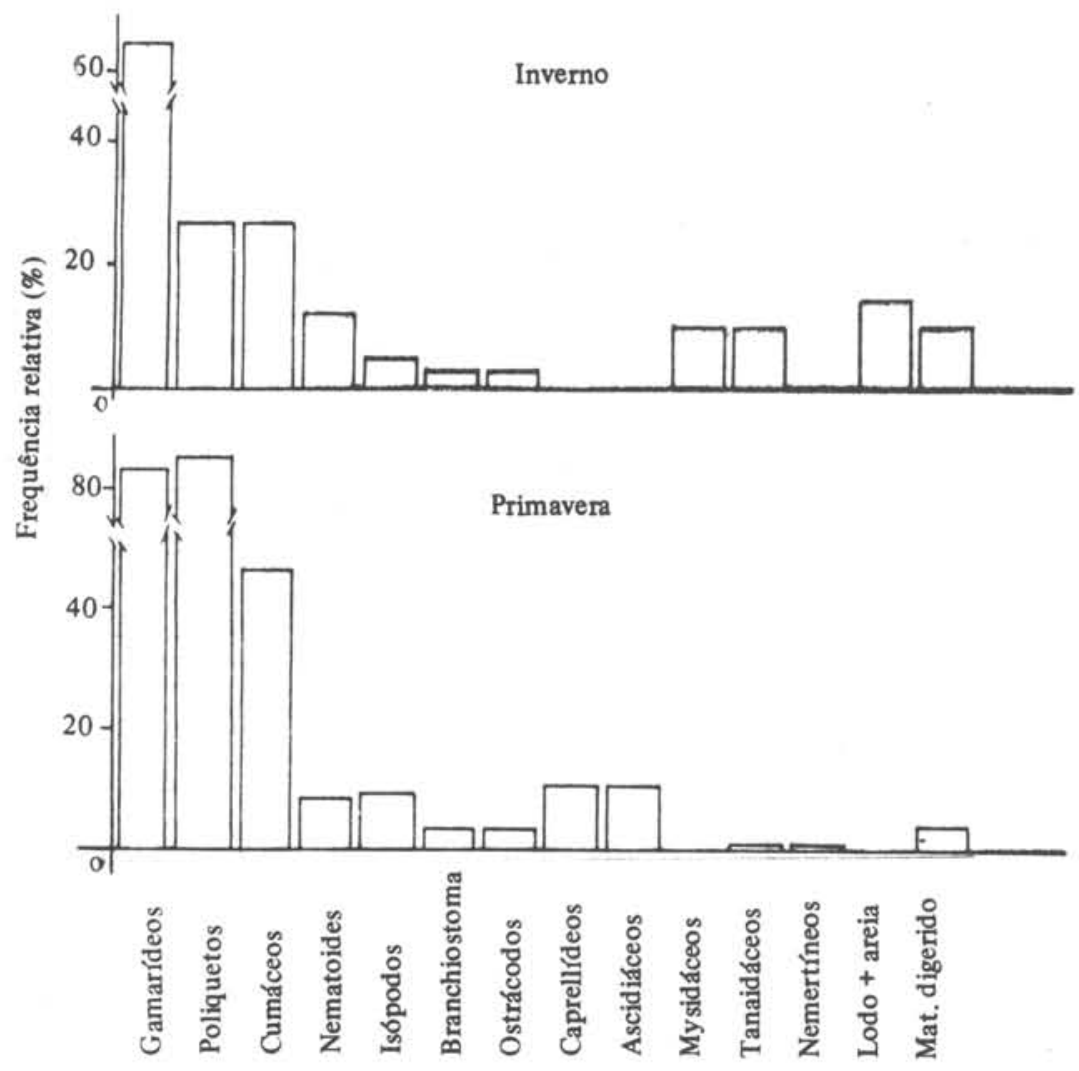

Fig. 1. Frequiência de ocorrência dos ítens alimentares de $E$. longimanus, no inverno e na primavera
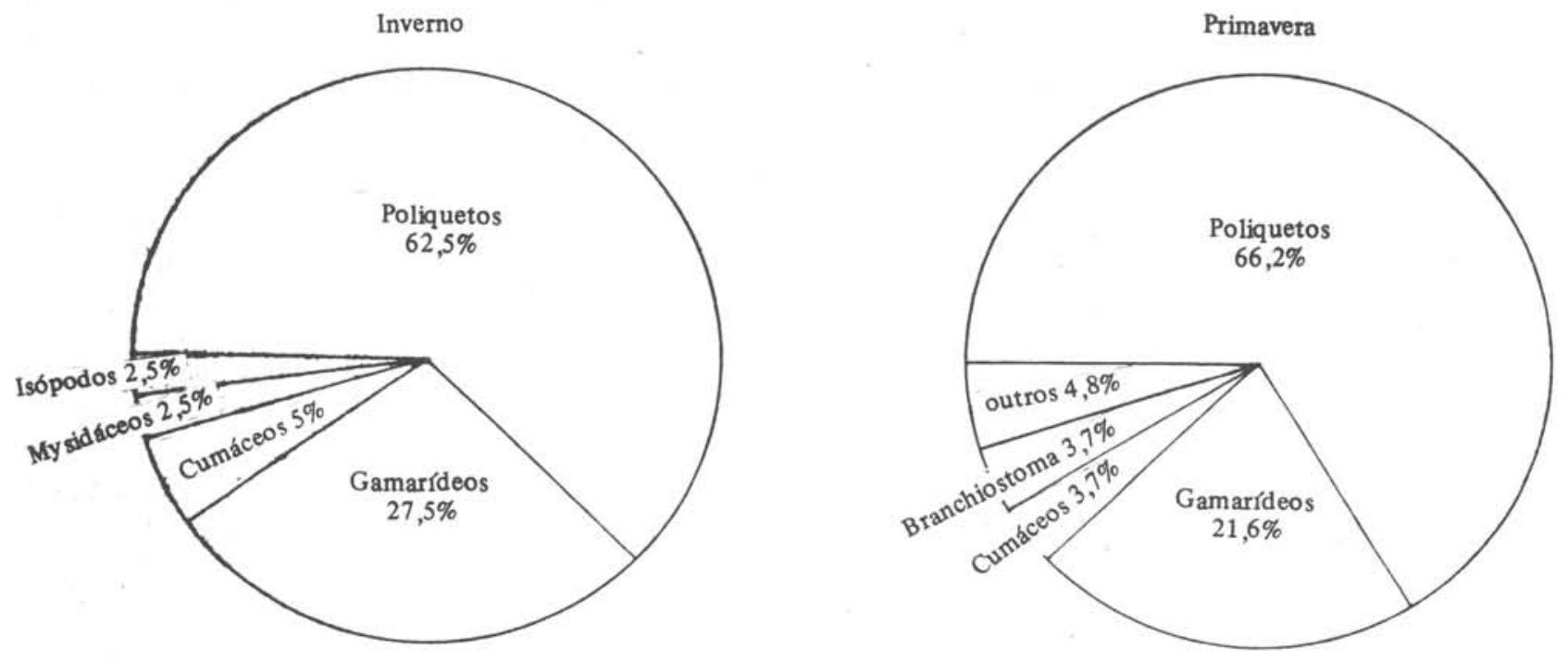

Fig. 2. Volume porcentual dos ítens alimentares de $E$. longimanus, no inverno e primavera 
Tabela I - Valores porcentuais da freqüência de ocorrência (Fi) e volume (Vi) de cada ítem alimentar (i), do produto desses valores e dos "indices alimentares" (lAi) no inverno e primavera, para Etropus longimanus, na plataforma continental do Rio Grande do Sul, em 1972.

\begin{tabular}{|c|c|c|c|c|c|c|c|c|}
\hline \multirow[b]{2}{*}{ Item alimentar } & \multicolumn{4}{|c|}{ Inverno $(\mathrm{N}=42$ ) } & \multicolumn{4}{|c|}{ Primavera $(\mathrm{N}=84)$} \\
\hline & $\mathrm{Fi}$ & $\mathrm{Vi}$ & $F_{i} \times V_{i}$ & IAi & $\mathrm{Fi}$ & $\mathrm{Vi}$ & $F_{i} \times V_{i}$ & $\mathrm{IAi}$ \\
\hline Gamarídeos & 64,3 & 27,5 & 1768,25 & 0,49 & 83,3 & 21,6 & 1799,28 & 0,23 \\
\hline Poliquetos & 26,2 & 62,5 & 1637,50 & 0,45 & 85,7 & 66,2 & 5673,34 & 0,74 \\
\hline Cumáceos & 26,2 & 5,0 & 131,00 & 0,04 & 46,4 & 3,7 & 171,68 & 0,02 \\
\hline Isópodos & 4,8 & 2,5 & 12,00 & 0,003 & 9,5 & 1,5 & 14,25 & 0,002 \\
\hline Branchiostoma & 2,4 & -5 & 0,00 & - & 3,6 & 3,7 & 13,32 & 0,002 \\
\hline Mysidáceos & 9,5 & 2.5 & 23,75 & 0,007 & 1,2 & - & - & - \\
\hline Ostrácodos & 2,4 & & 0,00 & - & 3,6 & - & - & - \\
\hline Tanaidáceos & 9,5 & & 0,00 & & 1,2 & - & - & - \\
\hline Caprellídeos & & & & & 10,7 & 1,5 & 16,05 & 0,002 \\
\hline Ascidiáceos & & & - & - & 10,7 & 1,8 & 19,26 & 0,002 \\
\hline Nematoides & 11,9 & & 0,00 & - & 8,3 & - & 0,00 & - \\
\hline Mat digerido & 9.5 & & 0,00 & & 4,8 & - & 0,00 & - \\
\hline Nemertíneos & & & - & - & 1,2 & 0,1 & 0,12 & 0,000 \\
\hline Lodo areia & 14.3 & & 0,00 & - & - & - & - & - \\
\hline
\end{tabular}

= Valor não possivel de ser determinado

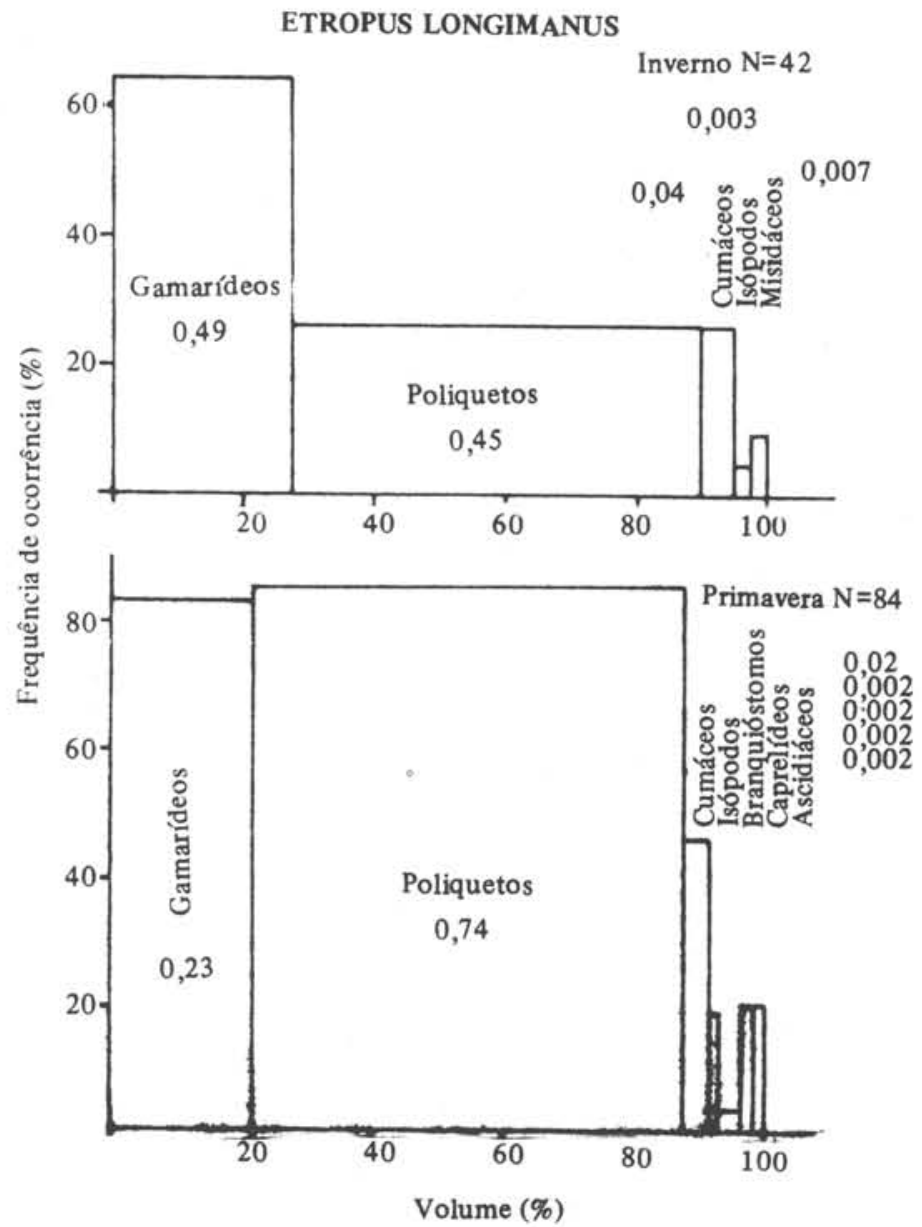

Fig. 3. Freqüência de ocorrência e volume porcentual dos diferentes ítens alimentares e seus respectivos índices alimentares 